\title{
Proposal of Umezawaea gen. nov., a new genus of the Actinosynnemataceae related to Saccharothrix, and transfer of Saccharothrix tangerinus Kinoshita et al. 2000 as Umezawaea tangerina gen. nov., comb. nov.
}

\author{
D. P. Labeda ${ }^{1}$ and R. M. Kroppenstedt ${ }^{2}$
}

Correspondence

D. P. Labeda

david.labeda@ars.usda.gov

\author{
${ }^{1}$ Microbial Genomics and Bioprocessing Research Unit, National Center for Agricultural Utilization \\ Research, Agricultural Research Service, US Department of Agriculture, Peoria, IL 61604 USA \\ ${ }^{2}$ DSMZ - German Collection of Microorganisms and Cell Cultures, Braunschweig, Germany
}

During phylogenetic analyses of the $16 \mathrm{~S}$ rRNA gene sequences of all taxa within the suborder Pseudonocardineae using the ARB software package (Ludwig et al., 2004), it was observed that Saccharothrix tangerinus MK27-91F2 ${ }^{\mathrm{T}}$ is misplaced within the genus Saccharothrix. Regardless of the phylogenetic algorithm used, this strain appears consistently as an outgroup from the species of Saccharothrix and is distinct from members of other genera in the family, including Crossiella cryophila NRRL B-16238 ${ }^{\mathrm{T}}$ and Goodfellowia coeruleoviolacea NRRL B- $23058^{\mathrm{T}}$, formerly classified within the genus Saccharothrix, as can be observed in Fig. 1. The phylogenetic trees reconstructed using sequences for all taxa with validly published names within the suborder exhibit the same tree topography (data not shown). The 16S rRNA gene sequence similarity of MK27$91 \mathrm{~F} 2^{\mathrm{T}}$ to all of the species of Saccharothrix is consistently below $96 \%$ and exhibits values quite similar to those observed between Lechevalieria species and members of the genus Saccharothrix (Supplementary Table S1, available in IJSEM Online). The 16S rRNA gene sequence similarity among species of the genus Saccharothrix ranges from $99.20 \%$ to a low of $96.96 \%$, between Saccharothrix

A 165 rRNA gene sequence similarity matrix is available as supplementary material with the online version of this paper. texasensis NRRL B-16134 ${ }^{\mathrm{T}}$ and Saccharothrix longispora NRRL B-16116 ${ }^{\mathrm{T}}$, another consistent, but not so distant, outlier in phylogenetic analyses of this genus.

An examination of the nucleotide signatures present in the $16 \mathrm{~S}$ rRNA gene sequence (Fig. 2) compared with those previously described for Saccharothrix and closely related genera (Labeda et al., 2001) revealed a pattern different from those diagnostic of the genera Actinokineospora (data not shown), Actinosynnema, Crossiella, Goodfellowia, Lechevalieria, Lentzea and Saccharothrix, providing further evidence of the uniqueness of $S$. tangerinus. It should be noted that $S$. longispora exhibits the $16 \mathrm{~S}$ rRNA gene nucleotide signature pattern typical of the genus Saccharothrix (Fig. 2) as well as sequence similarity values of $>97.5 \%$ to the vast majority of other species in this genus (Supplementary Table S1) and has a chemotaxonomic profile typical of Saccharothrix.

The original description of $S$. tangerinus (Kinoshita et al., 1999) documented the fragmentation of the aerial mycelium into ovoid to cylindrical elements, typical of many genera within the suborder Pseudonocardineae, but also described the production of pseudosporangia on the aerial mycelia of this strain, unlike any of the other genera in the suborder. Moreover, the chemotaxonomic profile for 


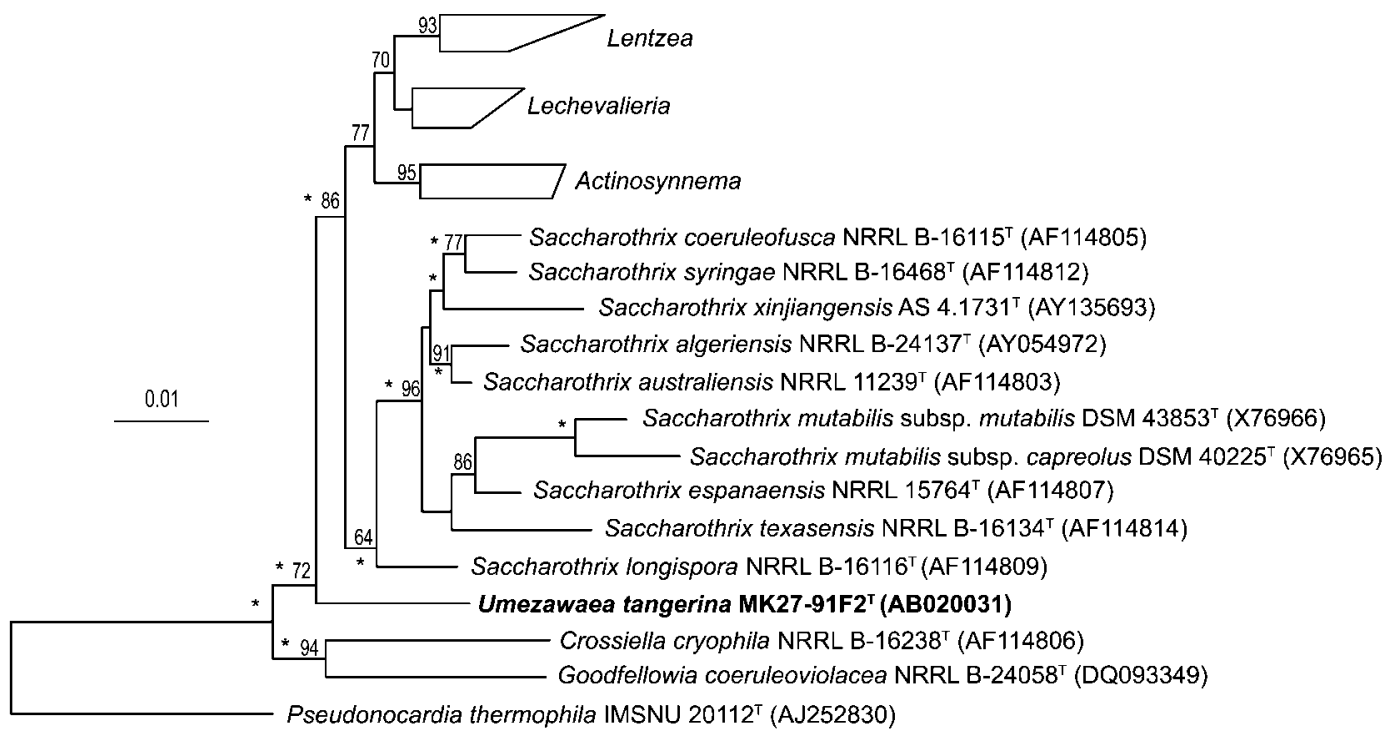

Fig. 1. Phylogenetic dendrogram reconstructed for the genera of the family Actinosynnemataceae most related to Saccharothrix and two taxa originally classified as Saccharothrix species calculated within ARB (Ludwig et al., 2004) from almost-complete 16S rRNA gene sequences using Kimura's evolutionary distance methods (Kimura, 1980) and the neighbourjoining method of Saitou \& Nei (1987), illustrating the taxonomic position of Umezawaea tangerina gen. nov., comb. nov. MK27$91 \mathrm{~F}^{\top}$ relative to the other taxa within the family. The taxa and sequences included in the genus groups are: Actinosynnema mirum DSM $43827^{\top}$ (GenBank accession no. X84447), Actinosynnema pretiosum subsp. pretiosum NRRL B-16060 ${ }^{\top}$ (AF114800), Lechevalieria aerocolonigenes NRRL B-3298 ${ }^{\top}$ (AF114804), Lechevalieria flava NRRL B-16131 ${ }^{\top}$ (AF114808), Lechevalieria fradiae CGMCC 4.3506 ${ }^{\top}$ (AY114175), Lentzea albida NBRC 16102 ${ }^{\top}$ (AB006176), Lentzea albidocapillata IMMIB D-958 ${ }^{\top}$ (X84321), Lentzea flaviverrucosa AS 4.0578 ${ }^{\top}$ (AF183957), Lentzea californiensis NRRL B-16137 (AF174435), Lentzea koreensis LM 121 ${ }^{\top}$ (Y09158), Lentzea violacea LM 036 ${ }^{\top}$ (AJ242633) and Lentzea waywayandensis NRRL B-16159 ${ }^{\top}$ (AF114813). Percentages at nodes represent levels of bootstrap support from 1000 resampled datasets; values less than $50 \%$ are not shown. Asterisks indicate that the corresponding branches that were also recovered in the maximum-likelihood (Felsenstein, 1993; Olsen et al., 1994) and maximum-parsimony (Felsenstein, 1993) trees. Bar, 0.01 nucleotide substitutions per site.

this strain, as shown in Table 1 , is different from those of the other genera in the Actinosynnemataceae as well as the closely related genera Crossiella and Goodfellowia. Moreover, the fatty acid profile of this strain is different from those of the other species of Saccharothrix (Table 2).
Strain MK27-91F2 $2^{\mathrm{T}}$ therefore appears distinct from members of the genus Saccharothrix sensu stricto as well as all of the other genera within the Pseudonocardineae, and a new genus, to be named Umezawaea gen. nov., is proposed to accommodate Saccharothrix tangerinus as the new combination Umezawaea tangerina gen. nov., comb. nov.
Lechevalieria aerocolonigenes NRRL B-3298 ${ }^{\top}$ Lentzea aibidocapillata DSM 44073

Actinosynnerna mirum DSM $43827^{\top}$

S. australiensis NRRL $11239^{\top}$

S. algeriensis NRRL B-24137 ${ }^{\top}$

S. coeruleofusca NRRL B-16115

S. espanaensis NRRL $15764^{\top}$

S. mutabiiis subsp. mutabilis DSM $43853^{\top}$

S. mutabilis subsp. capreolus DSM $40225^{\top}$

S. longispora NRRL B-16116'

S. syringiae NRRL B-16468

S. texasensis NRRL B-16134

S. xinjiangensis AS $4.1731^{\top}$

Umezawaea tangerina MK27-91F2

Crassiella cryophila NRRL B-16238

Goodfellowia coeruleoviolacea NRRL B-24058

Pseudonocardia thermophila IMSNU $20112^{\top}$
601

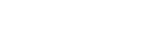

ACTTGGGGCT TAACCCCGAG CCTGCGGTCG

$\ldots \ldots \ldots \ldots$. $\ldots$. $\ldots$ A $\ldots$ T. . .

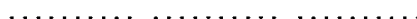

......CAC. .....GTG. ........

..... cac. ......GTG. .......

$\ldots \ldots$ CAC. $\ldots \ldots$ GTG. $\ldots \ldots \ldots$

$\ldots \ldots$ CAC. .....GTG. .......

......CAC. ... . . GTG. .......

..... CAC. . . . . GTG. ........

..... CAC. .....GTG. .......

...... CAC. ....GTG. .......

.....CAC. ....GGG. ........

...... CAC. .....GTG. .......

.....ACA. .....TGT. G..G...A.

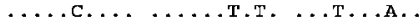

............ G. . . . .

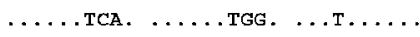

847

ACGTTCTCCG

... CC... T.

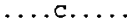

$\ldots . . . .$.

$\ldots . c \ldots$

$\ldots$......

$\ldots . \ldots \ldots$

$\ldots . . . .$.

$\ldots . \ldots \ldots$

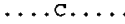

$\ldots, \ldots \ldots$

...c....

$\ldots . c \ldots$

.........

...GC....

...GC....

...GGT...
Fig. 2. Nucleotide signatures in the $16 \mathrm{~S}$ rRNA gene in Saccharothrix and related taxa. N, Undetermined nucleotide. 
Table 1. Chemotaxonomic characteristics of Umezawaea gen. nov. compared with other similar members of the family Actinosynnemataceae

All genera have meso-diaminopimelic acid as the cell-wall diamino acid and are of cell-wall chemotype III.

\begin{tabular}{|c|c|c|c|c|}
\hline Genus & Whole-cell sugar pattern ${ }^{\star}$ & Phospholipid type & Phospholipid(s) $\dagger$ & $\begin{array}{c}\text { Predominant } \\
\text { menaquinone(s) }\end{array}$ \\
\hline Umezawaea & Gal, Man, Rib, Rha (trace) & PII & $\begin{array}{l}\text { PE, PI, OH-PE, lyso-PE, } \\
\text { DPG, PIM }\end{array}$ & MK-9 $\left(\mathrm{H}_{4}\right)$; trace MK-10 $\left(\mathrm{H}_{4}\right)$ \\
\hline Actinokineospora & Gal, Man, Rha & PII & $\mathrm{PE}$ & MK-9 $\left(\mathrm{H}_{4}\right)$ \\
\hline Actinosynnema & Gal, Man & PII & PE, OH-PE, PI, PIM, DPG & MK-9 $\left(\mathrm{H}_{4}\right) ; \operatorname{MK}-9\left(\mathrm{H}_{6}\right)$ \\
\hline Crossiella & Gal, Rha, Rib & PII & PE, DPG, PI, PIM, PME & MK-9 $\left(\mathrm{H}_{4}\right)$ \\
\hline Goodfellowia & Gal, Rib & PII & PE, OH-PE, DPG & MK-10 $\left(\mathrm{H}_{4}\right) ; \mathrm{MK}-9\left(\mathrm{H}_{4}\right)$ \\
\hline Lechevalieria & Gal, Man, Rha & PII & $\mathrm{PE}$ & MK-9 $\left(\mathrm{H}_{4}\right)$ \\
\hline Lentzea & Gal, Man, Rib & PII & PE, DPG, PG, PI & MK-9 $\left(\mathrm{H}_{4}\right)$ \\
\hline Saccharothrix & Gal, Rha, Man (trace) & PII, PIV & PE, OH-PE, PI, PIM, DPG, PG (v) & MK-10 $\left(\mathrm{H}_{4}\right) ; \mathrm{MK}-9\left(\mathrm{H}_{4}\right)$ \\
\hline
\end{tabular}

${ }^{\star}$ Gal, Galactose; Man, mannose; Rha, rhamnose; Rib, ribose.

$†$ DPG, Diphosphatidylglycerol; PE, phosphatidylethanolamine; OH-PE, PE with hydroxy fatty acids; lyso-PE, PE where one fatty acid chain is missing from the glycerol backbone; PG, phosphatidylglycerol; PI, phosphatidylinositol; PIM, phosphatidylinositol mannosides; PME, phosphatidylmethylethanolamine.

Table 2. Comparison of fatty acid patterns of Umezawaea tangerina gen. nov., comb. nov. with those of Saccharothrix type strains

Values are percentages of total fatty acids. Data for Saccharothrix were taken from Grund \& Kroppenstedt (1990) and are given as means and as ranges of values for Saccharothrix syringae DSM $43886^{\mathrm{T}}$, S. mutabilis subsp. mutabilis DSM 43853 ${ }^{\mathrm{T}}$, S. longispora DSM $43749^{\mathrm{T}}$ and S. coeruleofusca DSM $43679^{\mathrm{T}}$. Values that differ significantly are highlighted in bold. Fatty acid concentrations $<1 \%$ may not be significant. - , Not detected.

\begin{tabular}{|c|c|c|c|}
\hline \multirow[t]{2}{*}{ Fatty acid } & \multicolumn{2}{|c|}{ Saccharothrix species } & \multirow[t]{2}{*}{ U. tangerina DSM $44270^{\mathrm{T}}$} \\
\hline & Range & Mean & \\
\hline iso- $14: 0$ & $0.93-6.43$ & 2.52 & 9.33 \\
\hline $14: 0$ & - & - & 0.41 \\
\hline iso- $15: 1$ & - & - & 0.77 \\
\hline iso- $15: 0$ & $4.12-21.02$ & 12.73 & 10.80 \\
\hline anteiso- $15: 0$ & $1.35-6.36$ & 3.16 & 3.42 \\
\hline $15: 1(c 9)$ & $0.00-0.06$ & 0.53 & 1.03 \\
\hline $15: 0$ & $0.47-0.92$ & 0.90 & 3.55 \\
\hline iso- $16: 1$ & $0.00-11.94$ & 5.54 & 5.90 \\
\hline iso- $16: 0$ & $30.67-60.56$ & 37.01 & 40.18 \\
\hline $16: 1(c 9)$ & $0.00-3.71$ & 1.49 & 3.82 \\
\hline iso- $15: 02-\mathrm{OH}$ & $0.00-3.07$ & 1.2 & - \\
\hline $16: 0$ & $0.47-4.00$ & 1.74 & 3.47 \\
\hline iso-16:0 10-methyl & - & - & 0.39 \\
\hline 16:0 9-methyl & $0.00-6.10$ & 4.49 & - \\
\hline 16:0 10-methyl & - & - & 3.10 \\
\hline anteiso- $17: 1$ & - & - & 0.39 \\
\hline iso- $17: 0$ & $0.83-7.63$ & 3.48 & 0.52 \\
\hline anteiso-17:0 & $2.99-13.52$ & 6.48 & 1.90 \\
\hline $17: 1(c 9)$ & $0.91-8.36$ & 4.40 & 3.03 \\
\hline iso-16:0 $2-\mathrm{OH}$ & $1.93-5.94$ & 4.03 & 4.02 \\
\hline $17: 0$ & $0.40-2.66$ & 1.58 & 2.11 \\
\hline iso-17:0 10 -methyl & - & - & 0.43 \\
\hline $17: 0$ 10-methyl & $0.00-1.71$ & 1.28 & 0.83 \\
\hline iso- $18: 0$ & $0.26-1.31$ & 0.55 & - \\
\hline $18: 1(c 9)$ & $0.00-3.43$ & 0.67 & - \\
\hline anteiso-17:0 2-OH & $0.29-1.80$ & 0.78 & - \\
\hline $18: 0$ 10-methyl & $0.00-0.39$ & 0.18 & - \\
\hline
\end{tabular}




\section{Description of Umezawaea gen. nov.}

Umezawaea (U.me.za'wa.e.a. N.L. fem. n. Umezawaea named for the late Hamao Umezawa, of the Institute of Microbial Chemistry, Tokyo, in recognition of his leadership and contributions to the study of the biology and natural products of actinomycetes).

Aerobic. Gram-positive, non-acid-fast, non-motile actinomycetes. Branched substrate mycelium (approx. 0.3$0.5 \mu \mathrm{m}$ in diameter) and, on some media, aerial mycelia are produced. Ovoid or cylindrical conidia $(0.3-0.5 \times 1.1-$ $1.9 \mu \mathrm{m})$ are produced by fragmentation of substrate mycelium. Pseudosporangia are produced on some media. Contains meso-diaminopimelic acid as the diamino acid. The muramic acid in the cell wall peptidoglycan is acetyl type. The whole-cell sugar pattern consists of galactose, mannose and ribose, with a trace of rhamnose. The phospholipid pattern consists predominantly of phosphatidylethanolamine, phosphatidylinositol, phosphatidylethanolamine containing hydroxylated fatty acids and lyso-phosphatidylethanolamine. The predominant menaquinone is MK-9 $\left(\mathrm{H}_{4}\right)$, with a trace of MK- $10\left(\mathrm{H}_{4}\right)$. Mycolic acids are absent. The $\mathrm{G}+\mathrm{C}$ content of the DNA is $74 \mathrm{~mol} \%$ (HPLC). Has a fatty-acid profile consisting predominantly of iso-16:0 fatty acids, with iso-14:0, iso-15:0, 16:0, $16: 1,17: 1$ and iso-16:1 as minor components. The phylogenetically nearest neighbour is the genus Saccharothrix. The type species is Umezawaea tangerina.

\section{Description of Umezawaea tangerina comb. nov.}

Umezawaea tangerina (tan.ge.ri' na. N.L. fem. adj. tangerina tangerine-coloured, referring to the colour of the vegetative growth).

Basonym: Saccharothrix tangerinus Kinoshita et al. 2000.

The description matches that published previously for Saccharothrix tangerinus by Kinoshita et al. (1999). The type strain is MK27-91F2 ${ }^{\mathrm{T}}\left(=\mathrm{NRRL}\right.$ B-24463 ${ }^{\mathrm{T}}=\mathrm{DSM}$ $44720^{\mathrm{T}}=$ FERM P-16053 $\left.3^{\mathrm{T}}=\mathrm{JCM} 10302^{\mathrm{T}}=\mathrm{NBRC}_{16184^{\mathrm{T}}}\right)$.

\section{Acknowledgements}

The assistance of Dr Jean Euzéby in providing the correct etymology for the proposed genus name and species epithet is gratefully acknowledged. Names are necessary to report factually on available data; however, the USDA neither guarantees nor warrants the standard of the product, and the use of the name by USDA implies no approval of the product to the exclusion of others that may also be suitable.

\section{References}

Felsenstein, J. (1993). PHYLIP (phylogeny inference package), version 3.5.1. Distributed by the author. Department of Genome Sciences, University of Washington, Seattle, WA, USA.

Grund, E. \& Kroppenstedt, R. M. (1990). Chemotaxonomy and numerical taxonomy of the genus Nocardiopsis. Int J Syst Bacteriol 40, 5-11.

Kimura, M. (1980). A simple method for estimating evolutionary rates of base substitutions through comparative studies of nucleotide sequences. J Mol Evol 16, 111-120.

Kinoshita, N., Igarashi, M., Ikeno, S., Hori, M. \& Hamada, M. (1999). Saccharothrix tangerinus sp. nov., the producer of the new antibiotic formamicin: taxonomic studies. Actinomycetologica 13, 20-31.

Kinoshita, N., Igarashi, M., Ikeno, S., Hori, M. \& Hamada, M. (2000). Saccharothrix tangerinus sp. nov. In Validation of Publication of New Names and New Combinations Previously Effectively Published Outside the IJSEM, List no. 74. Int J Syst Evol Microbiol 50, 949-950.

Labeda, D. P., Hatano, K., Kroppenstedt, R. M. \& Tamura, T. (2001). Revival of the genus Lentzea and proposal for Lechevalieria gen. nov. Int J Syst Evol Microbiol 51, 1045-1050.

Ludwig, W., Strunk, O., Westram, R., Richter, L., Meier, H., Yadhukumar, Buchner, A., Lai, T., Steppi, S. \& other authors (2004). ARB: a software environment for sequence data. Nucleic Acids Res 32, 1363-1371.

Olsen, G. J., Matsuda, H., Hagstrom, R. \& Overbeek, R. (1994). fastDNAml: a tool for construction of phylogenetic trees of DNA sequences using maximum likelihood. Comput Appl Biosci 10, 41-48.

Saitou, N. \& Nei, M. (1987). The neighbor-joining method: a new method for reconstructing phylogenetic trees. Mol Biol Evol 4, 406-426. 